\title{
Research Square \\ Prosets: making continued use of fossil fuels compatible with a credible transition to net zero
}

Eli Mitchell-Larson ( $\nabla$ eli.mitchell-larson@chch.ox.ac.uk)

University of Oxford https://orcid.org/0000-0002-3775-3482

Myles Allen

Environmental Change Institute, University of Oxford

\section{Research Article}

Keywords: carbon offsetting, sustainable emissions

Posted Date: March 19th, 2021

DOI: https://doi.org/10.21203/rs.3.rs-240578/v1

License: (c) (i) This work is licensed under a Creative Commons Attribution 4.0 International License. Read Full License 


\section{Abstract}

Interest in carbon offsetting is resurging among companies and institutions, but existing offerings fail to make continued use of fossil fuels compatible with a credible transition to sustainable net zero emissions. A clear definition of what makes an offset net-zero-compliant is needed. We introduce the 'proset', a new form of composite offset in which the fraction of carbon allocated to geological-timescale storage options increases progressively, reaching $100 \%$ by the target net zero date, generating predictable demand for effectively permanent $\mathrm{CO}_{2}$ storage while making the most of the near-term opportunities provided by nature-based climate solutions, all at an affordable cost to the offset purchaser.

\section{Background}

Is carbon offsetting a credible way of compensating for emissions from fossil fuels? While firms, investors, governments, non-state actors, and academics alike have wrestled with how to approach carbon offsetting for nearly two decades, this specific question is rarely satisfactorily answered. Before the COVID-19 pandemic induced a temporary dip in global emissions, a new offset boom was underway, characterised by increasing purchase volumes ${ }^{1,2}$ and interest in niche carbon removal techniques ${ }^{3,4}$. Organisations are increasingly committing to achieve net zero emissions of carbon dioxide $\left(\mathrm{CO}_{2}\right)$ before mid-century or as early as $2030^{5}$. Many of these entities depend on continued use of fossil fuels for activities such as international travel. At present, their only available options are to cease these activities entirely ${ }^{6}$ or attempt to neutralise their impact with carbon offsetting. The bulk of offsetting options available today are through nature-based climate solutions, whether emission reductions through avoided damage to ecosystems or carbon removal through forestation and other nature-based sequestration. Both of these options will no longer be available to offset fossil fuel emissions in a few decades' time. In a net-zero world, there is no scope for large-scale offsetting of emissions by paying for emission reductions because those reductions will already have occurred; and the impact of global warming itself is likely to substantially weaken, if not reverse, the strength of the biospheric carbon sink. Hence for continued offsetting of fossil fuel emissions to be compatible with a sustainable transition to net zero emissions, an increasing fraction of the carbon that underpins those offsets must be allocated to very long-term, geological-timescale, storage options ${ }^{7}$. We propose that this principle can be neatly packaged into a new offsetting instrument, termed a progressive offset or 'proset', generating demand for effectively permanent $\mathrm{CO}_{2}$ storage at an affordable cost while not undermining the strong case for immediate investment in shorter-term storage, much of which relies on critically needed nature-based climate solutions.

Offsetting is the act of paying a third party to compensate for the impact of one's own emissions through one of two actions: emission reduction or carbon removal. Emission reductions denote cases when the third party emits less $\mathrm{CO}_{2}$ relative to a counterfactual baseline (what they would have emitted in the absence of the offset contract). Carbon removals denote cases when $\mathrm{CO}_{2}$ is recovered directly from the atmosphere and stored. In many cases, the emission reduction or carbon removal involves storing the 
avoided or removed $\mathrm{CO}_{2}$, often in wild or managed ecosystems (forests, soil, etc.) or less commonly in geological formations (saline aquifers, disused oil and gas wells, etc.).

There are many challenges with ensuring the integrity of carbon offsets, documented in offsetting guides ${ }^{8}$, case studies ${ }^{9}$, and systematic reviews ${ }^{10}$. Key concerns affecting integrity include quantification (How much $\mathrm{CO}_{2}$ is actually avoided or taken up?), additionality (Might mitigation have taken place without the offsetting project? Has deforestation simply been displaced?) and permanence (Will a forest remain intact in perpetuity in the face of pests, fire, logging, agricultural development, and global warming itself? Does the offset delay rather than permanently avoid emissions? What is the risk that stored $\mathrm{CO}_{2}$ will be re-emitted to the atmosphere, and if so, how soon?). While all such criteria must be rigorously vetted to ensure integrity, we are chiefly concerned with the question of permanence. $\mathrm{CO}_{2}$ released by fossil fuel combustion elevates global temperatures for hundreds of thousands of years, so to be fully effective, any compensatory storage must, in effect, be equally permanent. Effective permanence can be accomplished either directly by employing $\mathrm{CO}_{2}$ storage techniques very low risks of reversal (e.g. chemical immobilisation of $\mathrm{CO}_{2}$ in basalt formations), or through financial mechanisms that insure any leakage event is remediated by "topping up" a comparable carbon sink. In this way, higher-risk storage techniques could be made "permanent", provided trust is maintained in the institutions and legal instruments used to ensure liability for remediating leaks.

Beyond offset quality criteria, there are two further overarching challenges that threaten to undermine the effectiveness of voluntary carbon offsetting. The first is the risk of overly-relying on emission reductions over carbon removals. Most currently-available carbon offsets come from emission reduction projects which, even if perfectly administered, are not sustainable in a net zero world. Once global emissions reach net zero, there will be no scope to compensate for ongoing emissions by paying a third party to reduce their emissions. Use of emission reductions must therefore be transitory and ultimately give way to exclusive reliance on removals.

Proset definition: A proset is a financial instrument that allows the purchaser to compensate for the impact of $\mathrm{CO}_{2}$ emissions from fossil fuel use by committing an equivalent quantity of $\mathrm{CO}_{2}$ to a combination of permanent and sub-permanent storage, with the fraction stored permanently increasing progressively over time following a path that is defined by the proset itself and consistent with $100 \%$ permanent storage by a specified target date. "Permanent" denotes storage that is expected to persist for longer than the 10,000-year timescales associated with geological storage, while sub-permanent denotes 100 years or greater, associated with the most secure storage options in the biosphere and oceans and with conventional storage time horizon expectations in offsetting markets.

Second, it is not possible to compensate indefinitely for continued use of fossil fuels through carbon removal with Nature-based Climate Solutions ( $\mathrm{NbCS}$, meaning the management of natural or humanmediated biological systems such as forests, grasslands, wetlands, and increasingly agricultural soils to enhance carbon storage). Large scale conversion of fossil carbon into biologically-stored carbon is 
inherently unsustainable because the global biosphere's capacity may be quite limited ${ }^{11}$. Projections of the rate of release of carbon from the biosphere by mid-century, for example through thawing tundra or increased wildfires, are similar to optimistic estimates of the potential global rate of carbon uptake by $\mathrm{NbCS}^{12}$. It is therefore possible that all available NbCS options will be required simply to prevent the global biosphere from further exacerbating global warming, leaving no additional capacity to compensate for ongoing fossil fuel emissions. Users of NbCS to compensate for fossil fuel emissions need to recognise that they are tapping into a rapidly depleting global resource which is under fierce competition from other land uses, primarily agriculture and timber management to provide food and fibre.

Despite these challenges, the global market for voluntary offsetts approached 100 million metric tonnes of carbon-dioxide equivalent $\left(\mathrm{MtCO}_{2} \mathrm{e}\right)$ in 2018 at an average price of around $\$ 3$ per tonne ${ }^{13}$. This highlights a further problem with the offset market as currently constituted: offset prices are typically too low to motivate buyers to reduce their own emissions, locking in high-carbon behaviour and investment.

Growing awareness of these problems with traditional offsetting has fuelled interest in specialised products that compensate for the impact of fossil fuel emissions by direct air capture of $\mathrm{CO}_{2}$ and permanent geological sequestration (DACCS) or remineralisation (converting $\mathrm{CO}_{2}$ into rock). These are currently much more expensive than traditional offsets (e.g. $\$ 775 / \mathrm{tCO}_{2}$ for DACCS ${ }^{3}$ ). An intermediate option, conventional carbon capture and storage, provides comparably-permanent storage at a cost that is an order of magnitude cheaper, bit faces challenges of public acceptability and is therefore less readily adaptable to generating voluntary carbon offsets.

In summary, any entity aiming to neutralise the impact of its fossil fuel emissions in the next few years is faced with an uncomfortable choice between 1 ) cheap but very possibly ineffective traditional carbon credits, 2) moderately more expensive but as-yet commercially unavailable conventional carbon capture and storage, and 3) unreproachable but extremely expensive and scarce DACCS.

\section{Prosets: A Progressive Transition To Permanent Co2 Storage}

The solution we propose is to define a new financial instrument, named a progressive offset or "proset", which allows the purchaser to compensate for the impact of their emissions by storing an equivalent quantity of $\mathrm{CO}_{2}$ in either the biosphere, oceans or lithosphere (the earth's crust). The defining characteristic of a proset is that the fraction of $\mathrm{CO}_{2}$ that is stored permanently increases progressively over time following a path that is defined by the proset itself. In this context, permanent storage may be interpreted as reservoirs with an effective lifetime greater than 10,000 years, corresponding to a leakage rate of less than $0.01 \%$ per year. The remaining $\mathrm{CO}_{2}$ in a proset is stored in reservoirs with a lifetime greater than 100 years, which would likely include well-managed afforestation and ecosystem restoration.

The time-evolution of the permanent storage fraction is specified in the full definition of a proset, which 
includes the start date, the end date, and the order of the polynomial describing the increase in the permanent storage fraction. In a $2^{\text {nd }}$-order 2020-2050 proset (illustrated in Figure 1), for example, this permanent fraction increases with time from 2020, divided by the time from 2020 to 2050, and raised to the power of two (hence $2^{\text {nd }}$-order). The permanent storage fraction would therefore be $(1 / 30)^{2}$, or $0.1 \%$, in $2021 ;(10 / 30)^{2}$, or $11 \%$, in 2030 ; and $(20 / 30)^{2}$, or $44 \%$, in 2040 . By 2050 , the specified net zero date, it would always reach $100 \%$. This is a general definition of a proset, but if only the end date is given, it must be assumed that the initial date is fixed to 2020, not the date on which prosets are adopted (to avoid unfairly benefiting late adopters).

Note that the unmodified definition of proset is agnostic to the source of $\mathrm{CO}_{2}$ for both the permanent and sub-permanent storage components. Given the challenges of developing a market for permanent $\mathrm{CO}_{2}$ storage, we believe it would make sense to allow any $\mathrm{CO}_{2}$ that would otherwise, under normal business practice, have ended up as unabated emissions into the atmosphere, to count towards the permanently stored fraction of a proset. This would allow $\mathrm{CO}_{2}$ capture at point sources, an emission reduction, to be utilised, provided this was not already being used to discharge some other obligation such as compliance with an emission trading system (which would compromise additionality). As point sources are brought under progressively tightening emission caps, an increasing fraction of $\mathrm{CO}_{2}$ would inevitably need to be sourced from carbon removal by more expensive direct air capture. Similarly, we assume that the subpermanent storage component also transitions rapidly from emission reduction options (e.g. avoided deforestation) to carbon removal (e.g. forestation or peatland restoration) in keeping with the volumes of removals needed to meet Paris temperature goals and the ultimate destination of $100 \%$ removals balancing any residual emissions. While we assume these transitions toward removals occur organically, proset adopters might choose to further specify the breakdown in the source types of $\mathrm{CO}_{2}$ used to generate their prosets. For example, some users might require that a progressive fraction of the permanent and/or sub-permanent storage used to create their proset come from carbon removals rather than emission reductions. For the permanent storage fraction, this would have the effect of providing targeted support for DACCS, remineralisation pathways, and perhaps enhanced weathering - all nascent technologies which will benefit from early investment. We believe emphasis is most usefully placed on the character and security of carbon storage (permanent vs. sub-permanent), not the source of the $\mathrm{CO}_{2}$ (removals vs. reductions). However, some would-be proset users may have sensitivities around the inclusion of certain point source emitters (e.g. bio-diesel refineries, natural gas processing) in a voluntary prosetting scheme. The proset model can easily accommodate such criteria provided the essence of the concept-a fundamental progression toward $100 \%$ permanent storage-is maintained.

By definition, a commitment to purchase prosets to cover ongoing fossil fuel emissions provides a predictable pathway to sustainable net zero by the target date, while also neutralising the warming impact of those emissions in the meantime, consistent with both the letter of corporate commitments to achieve net zero emissions as soon as possible, and also with the spirit of these commitments to sustainably end their contributions to global warming. It does so at a cost that we estimate is, in 2020 , no 
higher than that of many conventional, high-quality offsets, but which will increase as the net zero date approaches (see Figure 1).

In principle, as long as the permanently stored fraction rises to $100 \%$ by the proset end date, this provides a path to net zero regardless of shape. But the higher the order of the proset, the more the effort is backloaded (a $3^{\text {rd }}$-order 2050 proset would require only $(1 / 3)^{3}$, or $3.7 \%$, permanent storage in 2030 ). An observed result of least-cost ambitious mitigation scenarios from Integrated Assessment Models ${ }^{14}$ is that the fraction of global $\mathrm{CO}_{2}$ production that is permanently stored increases approximately quadratically, as in a $2^{\text {nd }}$-order proset, from 2020 to the date of net zero ${ }^{12}$. Further backloading this increase through the use of $3^{\text {rd }}$ or higher-order prosets would therefore impose a disproportionate fraction of the cost onto future decades, undermining the credibility of the commitment.

\section{The Case For Universally-defined Prosets}

Although it has been used to fund some laudable initiatives, the voluntary offsetting market has thus far failed to deliver a net zero-compliant instrument. Supply has greatly exceeded demand, resulting in very low prices and offsets of dubious quality. There are at least 10 competing standards, none of which addresses the need to transition to permanent storage. Many offsetting companies already allow purchasers to specify a mix of carbon offset types, but that mix is determined by purchasers' preferences, not what a sustainable net zero pathway requires.

The fact that, globally, the fraction of $\mathrm{CO}_{2}$ produced by the burning of fossil fuels that is permanently stored needs to rise to $100 \%$ by the time of global net zero emissions has long been noted ${ }^{15}$, but the concept of a time-evolving permanent storage fraction built into the design of an offset-like product, with a pre-specified profile to achieve sustainable net zero by a specific date is, to our knowledge, novel.

While recognising the dangers of a proliferation of terms, we believe that introducing a new word to define this concept may be helpful to avoid the definitional "race-to-the-bottom" that beset conventional offsets. The definition we propose is sufficiently general that it would apply to any monotonically increasing permanent stored fraction, and hence to any offset programme that is genuinely compatible with a sustainable transition to net zero. While we note the dangers of excessive backloading, we prefer to avoid freezing the definition at the outset, hoping to initiate an open discussion about the role of offsetting in the net zero transition.

A possible way forward would be for a coalition of academics, environmental NGOs, and offset service providers to work toward a universally acceptable proset definition, including both the profile (or order) of the proset and the permissible characteristics of both $\mathrm{CO}_{2}$ sources and storage options. As discussed above, we propose focusing on the character of storage and remaining agnostic to the sources of captured $\mathrm{CO}_{2}$, allowing point sources of $\mathrm{CO}_{2}$ to be used to generate prosets in advance of achieving global net zero emissions. Such an initiative could be stewarded by an established organisation such as WRI, CDP or the Science-Based Targets initiative. The advantage of a centrally-defined proset is that it 
could potentially be used to prevent the sale of proset-like products that would undercut the market by adopting a looser definition of "permanent", or a late-increasing profile that backloads the transition to permanent storage. The disadvantage is that it might discourage some adopters, particularly if prosets were clearly associated with a single profit-making supplier or certifying agency. This could be addressed by making a clear distinction between supply and certification, and entrusting a non-profit entity with a detailed and binding mandate to maintain proset integrity.

In terms of the broader role of carbon offsetting in the fight against climate change, we agree with Stephen Schneider's assessment: "I don't believe offsets are a distraction. But we'll have failed if that's all we do." ${ }^{16}$ Volunteerism has its limits, and concerted climate action eventually necessitates regulation. But voluntary carbon markets are more than just a placeholder. They can provide a testing ground for compliance markets, leading to regulation which uses voluntary action as evidence for what is possible. Prosets specifically offer a means of transitioning to permanent storage on a voluntary basis, a transition which we envision could one day be taken up by policymakers who wish to codify and enforce a balance of extracted carbon with permanent sinks ${ }^{15}$, representing durable net zero.

\section{Declarations}

Funding - The ClimateWorks Foundation, Environmental Change Institute, and Clarendon Scholarship provided funds and support necessary to complete this work.

Conflicts of interest/Competing interests - The authors declare no competing financial interest.

\section{References}

1. Gross, A., Hook, L. \& Powley, T. Boom times are back for carbon offsetting industry. https://www.ft.com/content/7e4665a2-1776-11 ea-8d73-6303645ac406 (2019).

2. Laville, S. 'Greta Thunberg effect' driving growth in carbon offsetting. The Guardian (2019).

3. Orbuch, R. Stripe's first negative emissions purchases. https://stripe.com/blog/first-negativeemissions-purchases (2020).

4. Joppa, L. Progress on our goal to be carbon negative by 2030. Microsoft on the Issues https://blogs.microsoft.com/on-the-issues/2020/07/21/carbon-negative-transform-to-net-zero/ (2020).

5. B Corp. 500+ B Corps Commit to Net Zero by 2030 | Certified B Corporation. https://bcorporation.net/news/500-b-corps-commit-net-zero-2030 (2019).

6. Allwood, J. et al.Absolute Zero. https://www.repository.cam.ac.uk/handle/1810/299414 (2019) doi:10.17863/CAM.46075.

7. Allen, M. et al.The Oxford Principles for Net Zero Aligned Carbon Offsetting. (2020).

8. Broekhoff, D., Gillenwater, M., Colbert-Sangree, T. \& Cage, P. Securing Climate Benefit: A Guide to Using Carbon Offsets. 59 https://www.sei.org/publications/guide-to-using-carbon-offsets/ (2019). 
9. Cavanagh, C. \& Benjaminsen, T. A. Virtual nature, violent accumulation: The 'spectacular failure' of carbon offsetting at a Ugandan National Park. Geoforum56, 55-65 (2014).

10. Galik, C. S. \& Jackson, R. B. Risks to forest carbon offset projects in a changing climate. For. Ecol. Manag.257, 2209-2216 (2009).

11. Griscom, B. W. et al. Natural climate solutions. Proc. Natl. Acad. Sci.114, 11645-11650 (2017).

12. Lowe, J. A. \& Bernie, D. The impact of Earth system feedbacks on carbon budgets and climate response. Philos. Trans. R. Soc. Math. Phys. Eng. Sci.376, 20170263 (2018).

13. Hamrick, K. \& Goldstein, A. Raising Ambition - State of the Voluntary Carbon Markets 2016. https://www.forest-trends.org/wp-content/uploads/imported/2016sovcm-report_10-pdf.pdf (2016).

14. Huppmann, D. et al. IAMC $1.5^{\circ} \mathrm{C}$ Scenario Explorer and Data hosted by IIASA. (2019) doi:10.5281/zenodo.3363345.

15. Allen, M. R., Frame, D. J. \& Mason, C. F. The case for mandatory sequestration. Nat. Geosci.2, 813814 (2009).

16. Ellison, K. Shopping for carbon credits. Salon https://www.salon.com/2007/07/02/carbon_credits/ (2007).

\section{Figures}

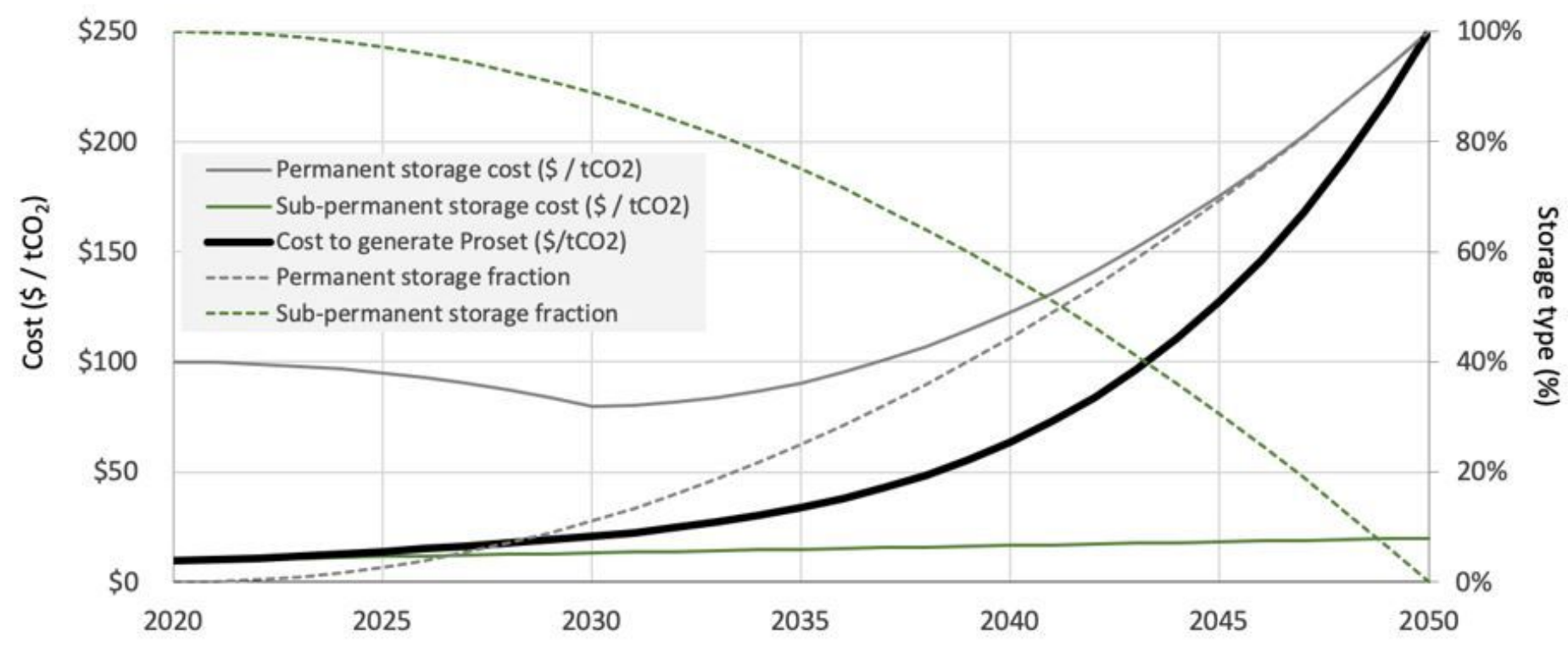

\section{Figure 1}

CO2 storage method and cost for a 2020-2050 2nd-order proset. An illustrative proset (2nd-order 20202050 , see text) with the percentages of sub-permanent (primarily biological) and permanent (primarily geological) storage as green and gray dashed lines respectively. The cost (solid lines) of sub-permanent storage is assumed to escalate linearly from $\$ 10 / \mathrm{tCO} 2$ in 2020 to $\$ 20 / \mathrm{tCO} 2$ in 2050 as the cheapest afforestation options are exhausted. Permanent storage costs represent the assumed full-chain cost to capture, transport, and store 1 ton of CO2. This is assumed to decline from an initial cost of $\$ 100 / \mathrm{tCO} 2$ in 
2020 to $\$ 80 /$ tCO2 in 2030 due to learning-by-doing as carbon storage projects begin to scale up. From 2030 to 2050, the dominant factor is assumed to be the declining availability of cheaper, high-purity point sources of $\mathrm{CO} 2$ and an ever-increasing reliance on low-purity streams of $\mathrm{CO} 2$ until DACCS or another carbon removal technique becomes the primry remaining means of obtaining $\mathrm{CO} 2$ to store. DACCS cost is assumed to drop to and plateau at $\$ 250 / \mathrm{tCO} 2$. 